\title{
A New Three-Oscillator Model for the Heart System in the Case of Time Delay and Designing Appropriate Controller for Its Synchronization
}

\author{
Siroos Nazari, ${ }^{1}$ Aghileh Heydari, ${ }^{2}$ Mahboobeh Tavakoli, ${ }^{3}$ and Javad Khaligh ${ }^{1}$ \\ ${ }^{1}$ Department of Mathematics, Payame Noor University, Tehran, Iran \\ ${ }^{2}$ Department of Mathematics, Payame Noor University, Mashhad, Iran \\ ${ }^{3}$ Department of Mathematics, Farhangian University, Mashhad, Iran
}

Correspondence should be addressed to Aghileh Heydari; a_heidari@pnu.ac.ir

Received 6 October 2013; Accepted 12 November 2013; Published 5 June 2014

Academic Editors: A. El-Sayed and C.-H. Lien

Copyright (C) 2014 Siroos Nazari et al. This is an open access article distributed under the Creative Commons Attribution License, which permits unrestricted use, distribution, and reproduction in any medium, provided the original work is properly cited.

\begin{abstract}
If the $S A$ and $A V$ oscillators are not synchronized, it may arise some kinds of blocking arrhythmias in the system of heart. In this paper, in order to examine the heart system more precisely, we apply the three-oscillator model of the heart system, and to prevent arrhythmias, perform the following steps. Firstly, we add a voltage with rang $a_{1}$ and $\omega$ frequency to $S A$ node. Then, we use delay time factor in oscillators and finally the appropriate control is designed. In this paper, we have explained how simulating and curing these arrhythmias are possible by designing a three-oscillator system for heart in the state of delay and without delay and by applying an appropriate control. In the end, we present the simulation results.
\end{abstract}

\section{Introduction}

As we know, If the $S A$ and $A V$ oscillators are not synchronized, it may cause some kinds of blocking arrhythmias in the system of the heart. At present, there are devices called pacemaker using electric shocks to synchronize if there is an arrhythmia. [1-3]. The main defect of these devices is the error of diagnosis and not having accurate control. For example, they sometimes apply shocking of 600 to 700 voltages to the heart wrongly even when there is no blocking at all, which is too dangerous. Applied shock to the heart muscle constricts all fibers concurrently and consequently all fibers return to recovery state and hope to return to their normal rhythm after that and it may sometimes occur that the patient involves blocking and the device have not diagnosed it so the patient dies. Two popular types of arrhythmias blocking and ectopic are interesting for researchers [4]. In order to simulate ectopic arrhythmias, a voltage ranging $a_{1}$ and $\omega$ frequency is added to $S A$ node.

\section{Three-Oscillator Modelling of the Heart without Time Delay}

As we know, cardiac normal rhythm is firstly produced by $S A$ node (normal pacemaker) and then causes stimulating of $A V$ node. Nevertheless, it has been observed that these two oscillators are not so accurate for producing ECG signal. This is because, the signal of first oscillator is related to the activation of $S A$ node and the right atrium and signal of second oscillator is only related to the depolarization of the left ventricular. Based on this hypothesis, it is possible to produce $P$ curve, but $Q R S$ complex may not be produced, because this interval is mainly due to ventricular repolarization [5]. These observations and also the existence of blocking arrhythmias force us to put the third oscillator which represents the spread of the pulse through ventricles, which physiologically represents His-Purkinje complex. To create a general model, we assume that there is a mutual coupling asymmetry among all oscillators [6]. In addition, external stimulation is entered 
into the system, considering periodic stimulus sentence to each oscillator. This developed model can be shown by a system of differential equations as shown below, in which a Vander pol equation has been considered to model $S A$ oscillator and another one to model the $A V$ oscillator and the third one to model HP oscillator [7]:

$$
\begin{aligned}
& (S A)\left\{\begin{aligned}
\dot{x}_{1}= & x_{2} \\
\dot{x}_{2}= & -d_{1}\left(x_{1}^{2}-1\right) x_{2}-c_{1} x_{1}+a_{1} \cos \omega t \\
& +R_{13}\left(x_{1}-x_{3}\right)+R_{15}\left(x_{1}-x_{5}\right),
\end{aligned}\right. \\
& (A V)\left\{\begin{aligned}
\dot{x}_{3}= & x_{4} \\
\dot{x}_{4}= & -d_{2}\left(x_{3}^{2}-1\right) x_{4}-c_{2} x_{3}+a_{2} \cos \omega t \\
& +R_{31}\left(x_{3}-x_{1}\right)+R_{35}\left(x_{3}-x_{5}\right),
\end{aligned}\right. \\
& (H P)\left\{\begin{aligned}
\dot{x}_{5}= & x_{6} \\
\dot{x}_{6}= & -d_{3}\left(x_{5}^{2}-1\right) x_{6}-c_{3} x_{5}+a_{3} \cos \omega t \\
& +R_{51}\left(x_{5}-x_{1}\right)+R_{53}\left(x_{5}-x_{3}\right),
\end{aligned}\right.
\end{aligned}
$$

in which pairs $\left(x_{1}, x_{2}\right),\left(x_{3}, x_{4}\right)$, and $\left(x_{5}, x_{6}\right)$ show $S A, A V$, and $H P$ oscillators, respectively.

To choose appropriate parameters from the Vander-pol system which are close to the system of the heart, we use trying and error test [8]. Regarding this test, appropriate parameters have been mentioned in Table 1 . By choosing parameters as shown in Table 1, any oscillator system is synchronized with another system that has different parameters. In the case that two systems are not synchronized, with the help of changing parameters and coupling coefficients, arrhythmias will occur $[9,10]$.

By changing $d_{1}, d_{2}$, and $d_{3}$ coefficients, we can produce different kinds of alternative responses. These coefficients influence the nonlinear sentence of the equation and cause stability of limit cycle in the phase plane $\left(x_{1}, x_{2}\right)$. Having limit cycle with the heart behavior is adapted physiologically to the behavior of the heart [11].

In the discussion of synchronization, synchronizing of the slow oscillators with the fast oscillators is done more easily. In the case of heart, slower pacemakers such as $A V$ and $H P$, should be synchronized with faster pacemakers such as $S A$. If it is not synchronized by changing the coupling coefficients, we try to synchronize oscillators by applying appropriate input controller to slow oscillators as shown below

$$
\begin{gathered}
(S A)\left\{\begin{aligned}
\dot{x}_{1}= & x_{2} \\
\dot{x}_{2}= & -d_{1}\left(x_{1}^{2}-1\right) x_{2}-c_{1} x_{1}+a_{1} \cos \omega t \\
& +R_{13}\left(x_{1}-x_{3}\right)+R_{15}\left(x_{1}-x_{5}\right),
\end{aligned}\right. \\
(A V)\left\{\begin{aligned}
\dot{x}_{3}= & x_{4} \\
\dot{x}_{4}= & -d_{2}\left(x_{3}^{2}-1\right) x_{4}-c_{2} x_{3}+a_{2} \cos \omega t \\
& +R_{31}\left(x_{3}-x_{1}\right)+R_{35}\left(x_{3}-x_{5}\right)+u_{1},
\end{aligned}\right. \\
(H P)\left\{\begin{aligned}
\dot{x}_{5}= & x_{6} \\
\dot{x}_{6}= & -d_{3}\left(x_{5}^{2}-1\right) x_{6}-c_{3} x_{5}+a_{3} \cos \omega t \\
& +R_{51}\left(x_{5}-x_{1}\right)+R_{53}\left(x_{5}-x_{3}\right)+u_{2} .
\end{aligned}\right.
\end{gathered}
$$

\begin{tabular}{|c|c|c|}
\hline Parameter & Definition & $\begin{array}{c}\text { Three-oscillators } \\
\text { system }\end{array}$ \\
\hline$c_{1}$ & $S A$ frequency & 1 \\
\hline$c_{2}$ & $A V$ frequency & 2 \\
\hline$c_{3}$ & $H P$ frequency & 1 \\
\hline$a_{1}$ & $S A$ voltage range & 5 \\
\hline$a_{2}$ & $A V$ voltage range & 6 \\
\hline$a_{3}$ & $H P$ voltage range & 4 \\
\hline$d_{1}$ & SA damping Coefficient & 5 \\
\hline$d_{2}$ & $A V$ damping Coefficient & 6 \\
\hline$d_{3}$ & HP damping Coefficient & 7 \\
\hline$\omega$ & Frequency & $2.001 \leq \omega<2.05$ \\
\hline$R_{i j}$ & $\begin{array}{l}\text { Coupling coefficients between } x_{i} \\
\text { and } x_{j}\end{array}$ & \\
\hline$R_{13}$ & & 1 \\
\hline$R_{15}$ & & 1 \\
\hline$R_{35}$ & & 1 \\
\hline$R_{51}$ & & 2 \\
\hline$R_{31}$ & & 5 \\
\hline$R_{53}$ & & 3 \\
\hline$x_{1}$ & $S A$ membrance flow & \\
\hline$x_{2}$ & $S A$ membrance voltage & \\
\hline$x_{3}$ & $A V$ membrance flow & \\
\hline$x_{4}$ & $A V$ membrance voltage & \\
\hline$x_{5}$ & HP membrance flow & \\
\hline$x_{6}$ & HP membrance voltage & \\
\hline
\end{tabular}

TABLE 1: Appropriate parameters to synchronize three-oscillator system.

The state variables of slow systems will be converged to state variables of fast system after a transient time. In fact, the second and third oscillators should follow the first oscillator which contains dominant frequency, so synchronization error is considered as follows [12]:

$$
\begin{array}{ll}
e_{1}=x_{1}-x_{3}, & e_{2}=x_{2}-x_{4}, \\
e_{3}=x_{3}-x_{5}, & e_{4}=x_{4}-x_{6} .
\end{array}
$$

The purpose of the synchronization is to annihilate errors. So, selected control functions to vanish errors as $\dot{e}_{i}=0$, $i=1,2,3,4$, are measured as follows:

$$
\begin{aligned}
\dot{e}_{1}= & \dot{x}_{1}-\dot{x}_{3}, \\
\dot{e}_{2}= & \dot{x}_{2}-\dot{x}_{4} \\
= & -d_{1}\left(x_{1}^{2}-1\right) x_{2}-c_{1} x_{1}+a_{1} \cos \omega t \\
& +R_{13}\left(x_{1}-x_{3}\right)+R_{15}\left(x_{1}-x_{5}\right)+d_{2}\left(x_{3}^{2}-1\right) x_{4} \\
& +c_{2} x_{3}-a_{2} \cos \omega t-R_{31}\left(x_{3}-x_{1}\right)-R_{35}\left(x_{3}-x_{5}\right)-u_{1},
\end{aligned}
$$




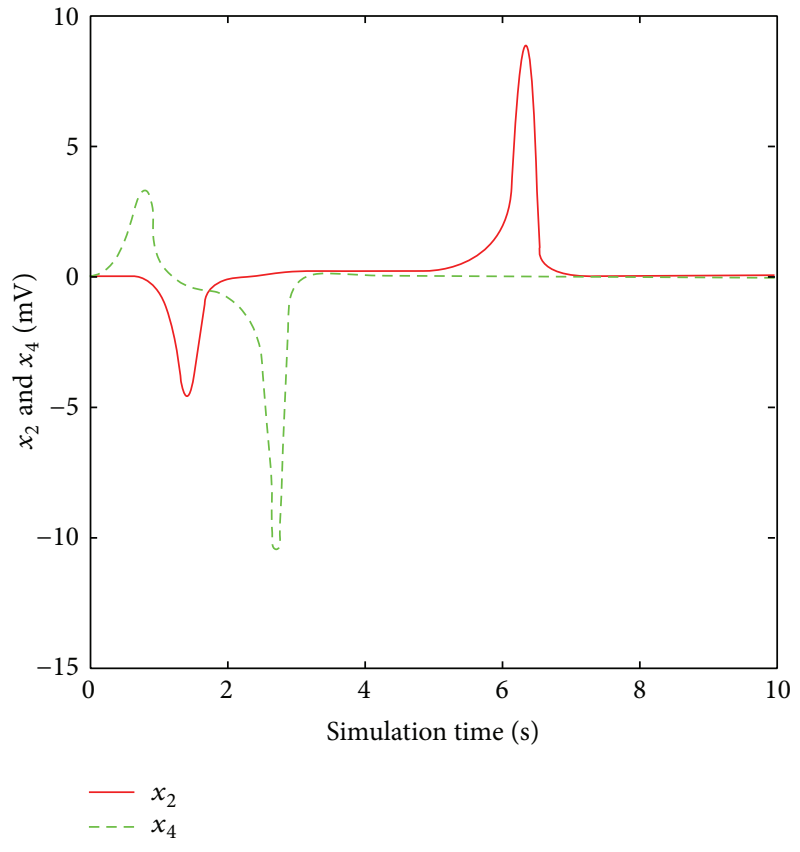

(a)

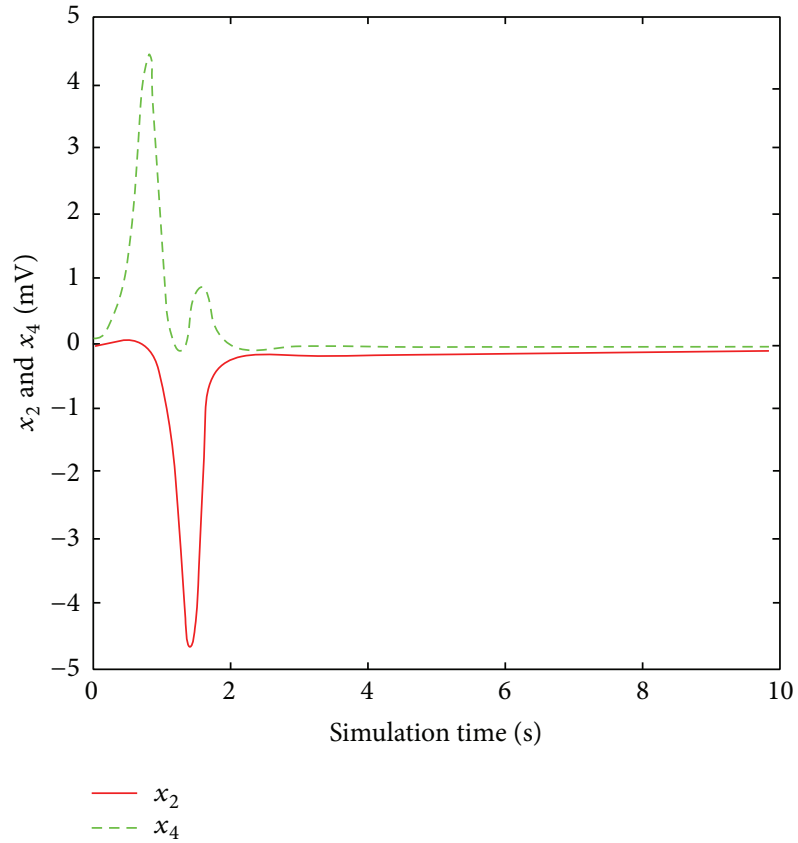

(b)

FIGURE 1: Synchronization of states $x_{2}, x_{4}$ without time delay befor control (a) and after control (b).

$$
\begin{aligned}
\dot{e}_{3}= & \dot{x}_{3}-\dot{x}_{5}, \\
\dot{e}_{4}= & \dot{x}_{4}-\dot{x}_{6} \\
= & -d_{2}\left(x_{3}^{2}-1\right) x_{4}-c_{2} x_{3}+a_{2} \cos \omega t \\
& +R_{31}\left(x_{3}-x_{1}\right)+R_{35}\left(x_{3}-x_{5}\right)+u_{1} \\
& +d_{3}\left(x_{5}^{2}-1\right) x_{6}+c_{3} x_{5}-a_{3} \cos \omega t \\
& -R_{51}\left(x_{5}-x_{1}\right)-R_{53}\left(x_{5}-x_{3}\right)-u_{2} .
\end{aligned}
$$

So, by choosing control rules as follows:

$$
\begin{aligned}
u_{1}= & -d_{1} x_{1}^{2} x_{2}+a_{1} \cos \omega t+d_{2} x_{3}^{2} x_{4}-c_{1} x_{3} \\
& -a_{2} \cos \omega t+d_{1} x_{4}+c_{2} x_{5}-d_{2} x_{2} \\
& +k_{1} e_{1}+k_{2} e_{2}+k_{3} e_{3}, \\
u_{2}= & -d_{2} x_{3}^{2} x_{4}+a_{2} \cos \omega t+d_{3} x_{5}^{2} x_{6} \\
& +c_{3} x_{5}-a_{3} \cos \omega t+\widehat{d}_{2} x_{6}-c_{2} x_{5} \\
& -d_{3} x_{4}+k_{4} e_{1}+k_{5} e_{3}+k_{6} e_{4}+u_{1}+k_{7},
\end{aligned}
$$

matrix form of error equations is

$$
\dot{e}=A e .
$$

By applying controllers $u_{1}$ and $u_{2}$, the results of simulations show that diagrams related to synchronization are tracking each other and

$$
\lim _{t \rightarrow \infty}\|e\|=0
$$

Simulation diagrams related to synchronization in the case of three oscillators without time delay have been shown below. See Figures 1, 2, and 3 (the horizontal axis time (s) and the vertical axis millivolts).

\section{Three-Oscillator Modelling of the Heart with Time Delay}

Since even small delays may change the dynamics of the system, including of time delay in differential equations can cause drastic changes and chaos in a system that has regular behavior [7,13]. Thus, system (1) is changed as below in which $\tau$ represents time delay and $x_{i}^{\tau}=x_{i}(t-\tau)$ :

$$
\begin{aligned}
& (S A)\left\{\begin{aligned}
\dot{x}_{1}= & x_{2} \\
\dot{x}_{2}= & -d_{1}\left(x_{1}^{2}-1\right) x_{2}-c_{1} x_{1}+a_{1} \cos \omega t \\
& +R_{13}\left(x_{1}-x_{3}^{\tau_{13}}\right)+R_{15}\left(x_{1}-x_{5}^{\tau_{15}}\right),
\end{aligned}\right. \\
& (A V)\left\{\begin{aligned}
\dot{x}_{3}= & x_{4} \\
\dot{x}_{4}= & -d_{2}\left(x_{3}^{2}-1\right) x_{4}-c_{2} x_{3}+a_{2} \cos \omega t \\
& +R_{31}\left(x_{3}-x_{1}^{\tau_{31}}\right)+R_{35}\left(x_{3}-x_{5}^{\tau_{35}}\right),
\end{aligned}\right. \\
& (H P)\left\{\begin{aligned}
\dot{x}_{5}= & x_{6} \\
\dot{x}_{6}= & -d_{3}\left(x_{5}^{2}-1\right) x_{6}-c_{3} x_{5}+a_{3} \cos \omega t \\
& +R_{51}\left(x_{5}-x_{1}^{\tau_{51}}\right)+R_{53}\left(x_{5}-x_{3}^{\tau_{53}}\right) .
\end{aligned}\right.
\end{aligned}
$$

By substitution, we will have

$$
(S A)\left\{\begin{aligned}
\dot{x}_{1}= & x_{2} \\
\dot{x}_{2}= & -d_{1}\left(x_{1}^{2}-1\right) x_{2}-c_{1} x_{1}+a_{1} \cos \omega t \\
& +R_{13}\left(x_{1}-x_{3}\left(t-\tau_{13}\right)\right) \\
& +R_{15}\left(x_{1}-x_{5}\left(t-\tau_{15}\right)\right),
\end{aligned}\right.
$$




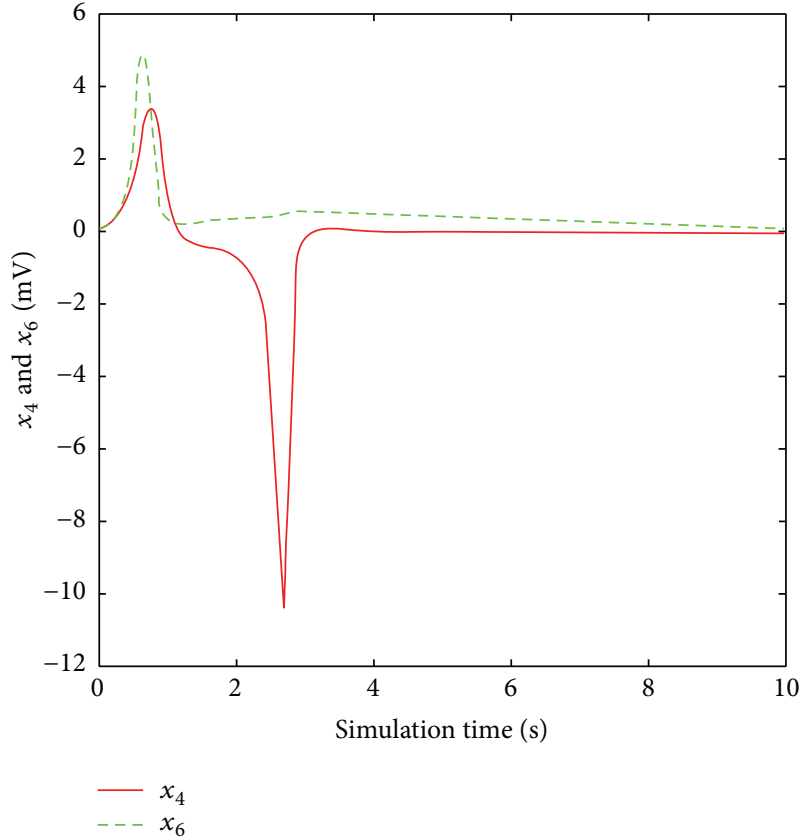

(a)

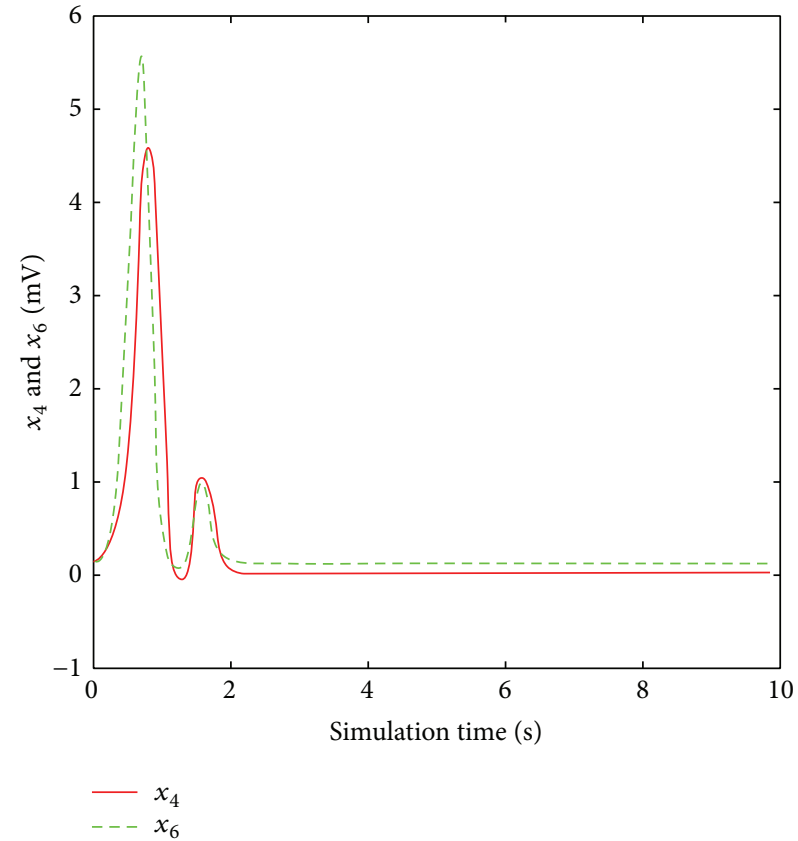

(b)

FIGURE 2: Synchronization of states $x_{4}, x_{6}$ without time delay befor control (a) and after control (b).

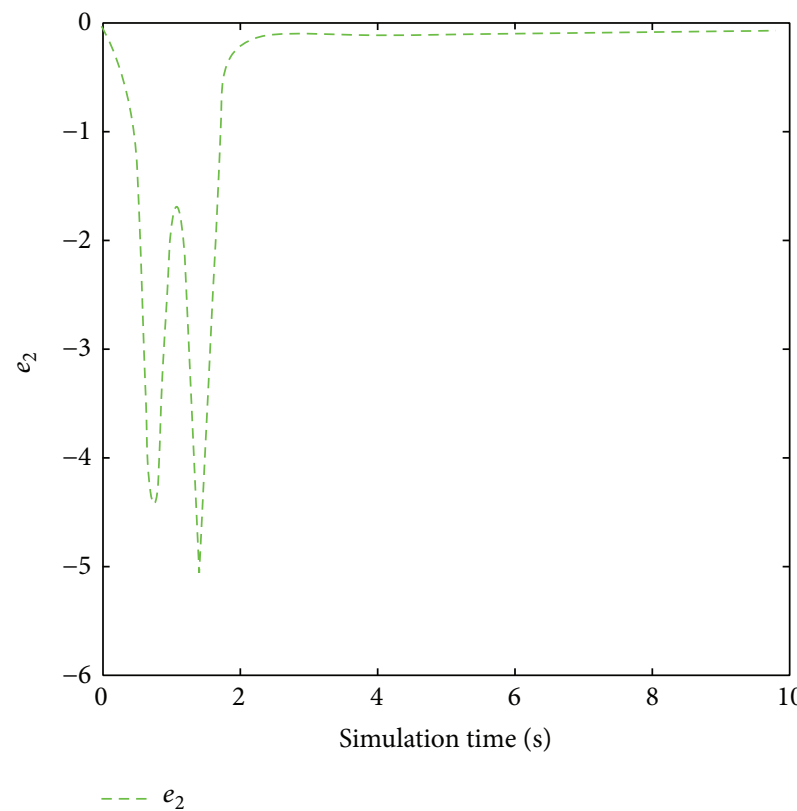

(a)

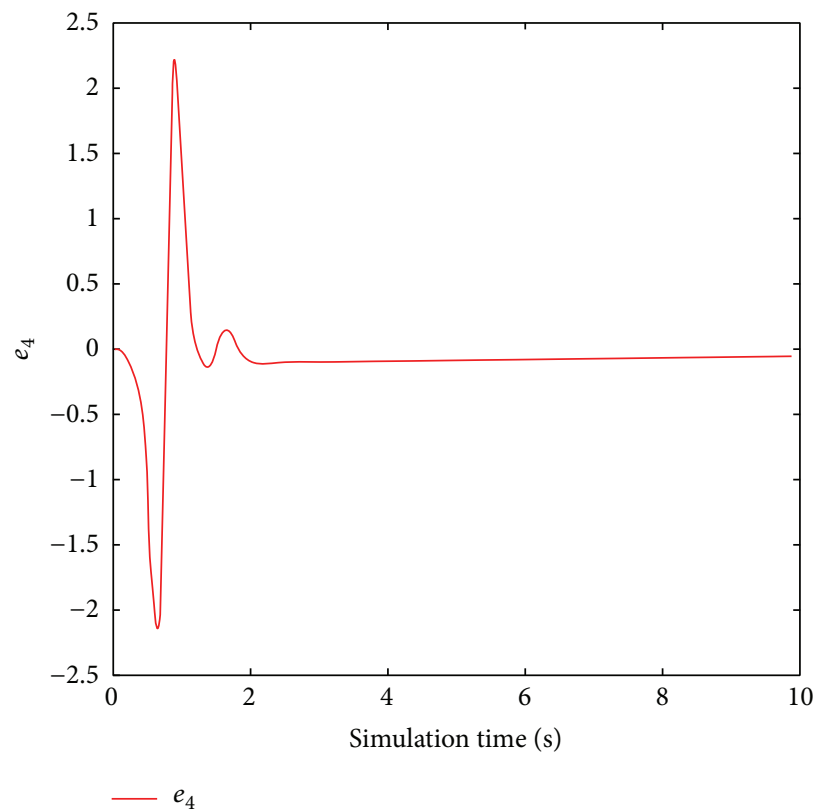

(b)

Figure 3: Error states $x_{2}, x_{4}$ and $x_{4}, x_{6}$ without time delay after control ((a), (b)).

$(A V)\left\{\begin{aligned} \dot{x}_{3}= & x_{4} \\ \dot{x}_{4}= & -d_{2}\left(x_{3}^{2}-1\right) x_{4}-c_{2} x_{3}+a_{2} \cos \omega t \\ & +R_{31}\left(x_{3}-x_{1}\left(t-\tau_{31}\right)\right) \\ & +R_{35}\left(x_{3}-x_{5}\left(t-\tau_{35}\right)\right)\end{aligned}\right.$ $(H P)\left\{\begin{aligned} \dot{x}_{5}= & x_{6} \\ \dot{x}_{6}= & -d_{3}\left(x_{5}^{2}-1\right) x_{6}-c_{3} x_{5}+a_{3} \cos \omega t \\ & +R_{51}\left(x_{5}-x_{1}\left(t-\tau_{51}\right)\right) \\ & +R_{53}\left(x_{5}-x_{3}\left(t-\tau_{53}\right)\right) .\end{aligned}\right.$ 


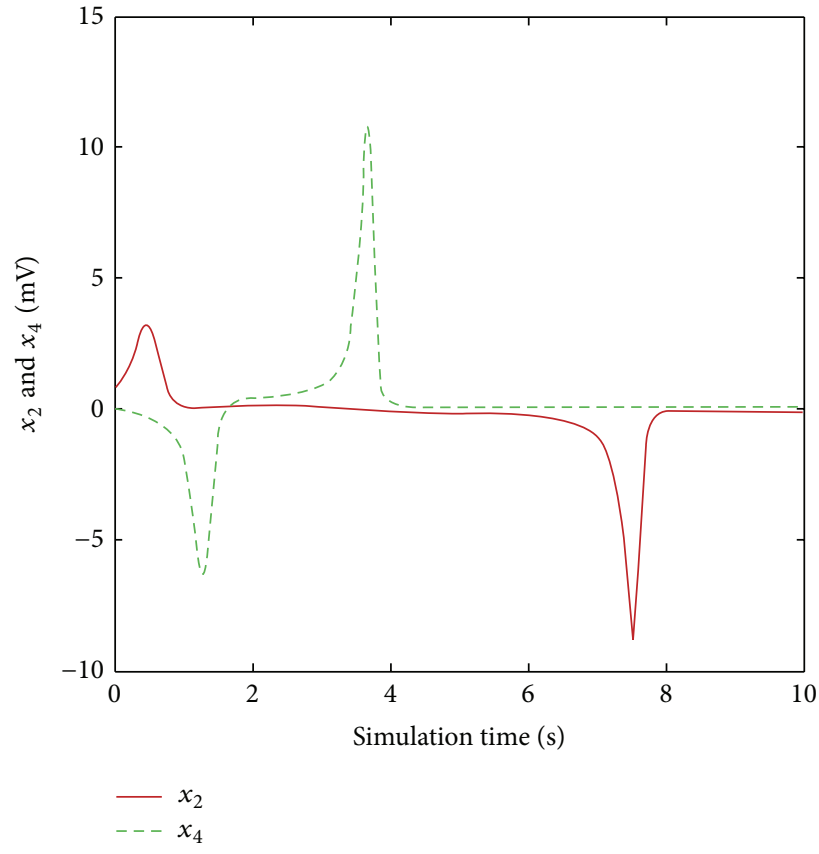

(a)

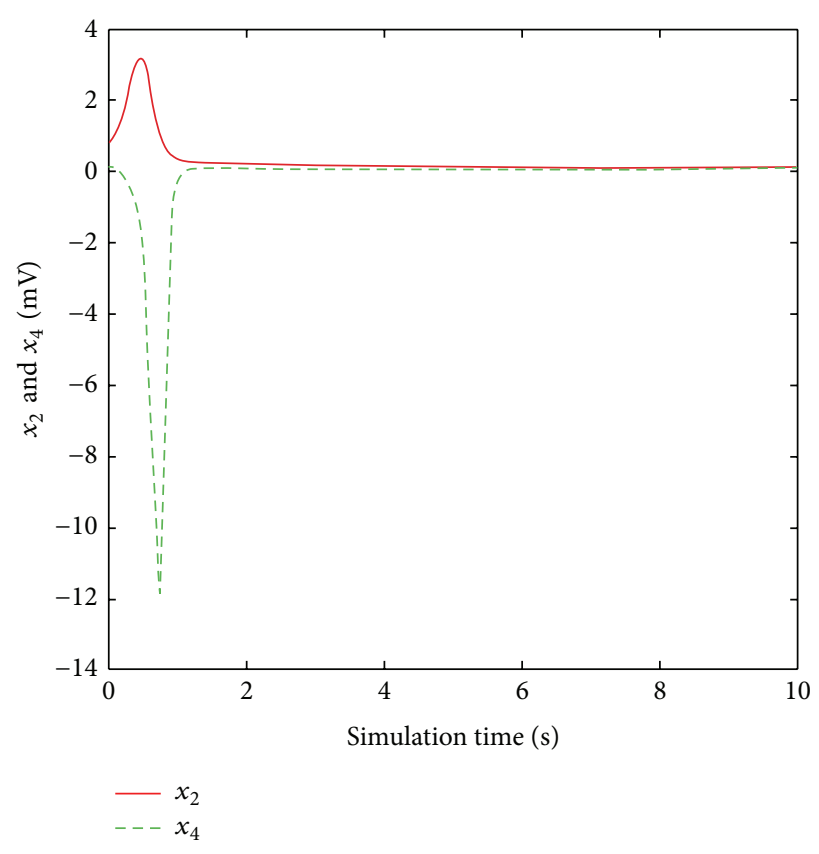

(b)

FIgURE 4: Synchronization of states $x_{2}, x_{4}$ with time delay befor control (a) and after control (b).

Now, by applying the appropriate controller on it which is as follows [14]:

$$
\begin{aligned}
& (S A)\left\{\begin{aligned}
\dot{x}_{1}= & x_{2} \\
\dot{x}_{2}= & -d_{1}\left(x_{1}^{2}-1\right) x_{2}-c_{1} x_{1}+a_{1} \cos \omega t \\
& +R_{13}\left(x_{1}-x_{3}\left(t-\tau_{13}\right)\right) \\
& +R_{15}\left(x_{1}-x_{5}\left(t-\tau_{15}\right)\right),
\end{aligned}\right. \\
& (A V)\left\{\begin{aligned}
\dot{x}_{3}= & x_{4} \\
\dot{x}_{4}= & -d_{2}\left(x_{3}^{2}-1\right) x_{4}-c_{2} x_{3}+a_{2} \cos \omega t \\
& +R_{31}\left(x_{3}-x_{1}\left(t-\tau_{31}\right)\right) \\
& +R_{35}\left(x_{3}-x_{5}\left(t-\tau_{35}\right)\right)+u_{1},
\end{aligned}\right. \\
& (H P)\left\{\begin{aligned}
\dot{x}_{5}= & x_{6} \\
\dot{x}_{6}= & -d_{3}\left(x_{5}^{2}-1\right) x_{6}-c_{3} x_{5}+a_{3} \cos \omega t \\
& +R_{51}\left(x_{5}-x_{1}\left(t-\tau_{51}\right)\right) \\
& +R_{53}\left(x_{5}-x_{3}\left(t-\tau_{53}\right)\right)+u_{2},
\end{aligned}\right.
\end{aligned}
$$

the state variables of slow systems will be converged to state variables of fast system, after a transient time. In fact, the second and third oscillators should follow the first oscillator containing dominant frequency, so synchronization error is considered as follows [11]:

$$
\begin{aligned}
& e_{1}(t)=x_{1}(t)-x_{3}\left(t-\tau_{13}\right), \\
& e_{2}(t)=x_{2}(t)-x_{4}\left(t-\tau_{24}\right), \\
& e_{3}(t)=x_{3}(t)-x_{5}\left(t-\tau_{35}\right), \\
& e_{4}(t)=x_{4}(t)-x_{6}\left(t-\tau_{46}\right) .
\end{aligned}
$$

The purpose of the synchronization is to annihilate errors. So, chose control functions to vanish errors as $\dot{e}_{i}=0, i=1,2,3,4$, that are measured as follows:

$$
\begin{aligned}
\dot{e}_{1}= & \dot{x}_{1}-\dot{x}_{3}\left(t-\tau_{13}\right), \\
\dot{e}_{2}= & \dot{x}_{2}-\dot{x}_{4}\left(t-\tau_{24}\right) \\
= & -d_{1}\left(x_{1}^{2}-1\right) x_{2}-c_{1} x_{1}+a_{1} \cos \omega t \\
& +R_{13}\left(x_{1}-x_{3}\left(t-\tau_{13}\right)\right)+R_{15}\left(x_{1}-x_{5}\left(t-\tau_{15}\right)\right) \\
& +d_{2}\left(x_{3}^{2}-1\right) x_{4}+c_{2} x_{3}-a_{2} \cos \omega t \\
& -R_{31}\left(x_{3}-x_{1}\left(t-\tau_{31}\right)\right)-R_{35}\left(x_{3}-x_{5}\left(t-\tau_{35}\right)\right)-u_{1}, \\
\dot{e}_{3}= & \dot{x}_{3}-\dot{x}_{5}\left(t-\tau_{35}\right), \\
\dot{e}_{4}= & \dot{x}_{4}-\dot{x}_{6} \\
= & -d_{2}\left(x_{3}^{2}-1\right) x_{4}-c_{2} x_{3}+a_{2} \cos \omega t \\
& +R_{31}\left(x_{3}-x_{1}\left(t-\tau_{31}\right)\right)+R_{35}\left(x_{3}-x_{5}\left(t-\tau_{35}\right)\right) \\
& +u_{1}+d_{3}\left(x_{5}^{2}-1\right) x_{6}+c_{3} x_{5}-a_{3} \cos \omega t-R_{51} \\
& \times\left(x_{5}-x_{1}\left(t-\tau_{51}\right)\right)-R_{53}\left(x_{5}-x_{3}\left(t-\tau_{53}\right)\right)-u_{2} .
\end{aligned}
$$

In this case,

$$
\begin{aligned}
\dot{e}_{2}= & \dot{x}_{2}-\dot{x}_{4}\left(t-\tau_{24}\right) \\
= & -d_{1} x_{1}^{2} x_{2}+d_{1} x_{2}+d_{1} x_{4}-d_{1} x_{4}-c_{1} x_{1}+c_{1} x_{3} \\
& -c_{1} x_{3}+a_{1} \cos \omega t+R_{13}\left(x_{1}-x_{3}\left(t-\tau_{13}\right)\right)
\end{aligned}
$$




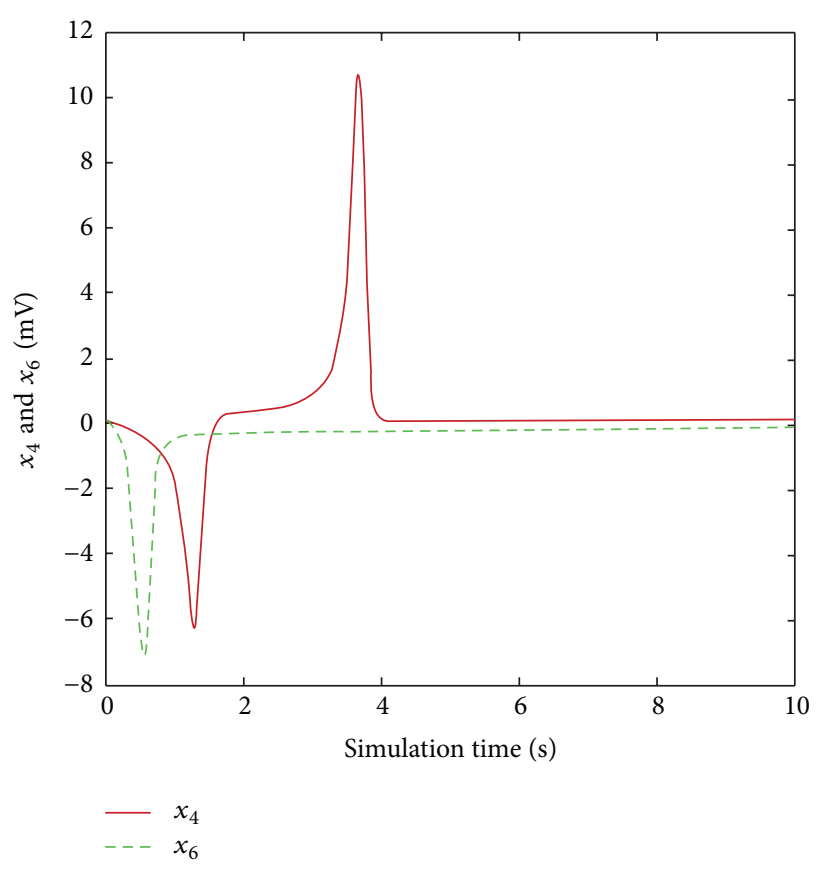

(a)

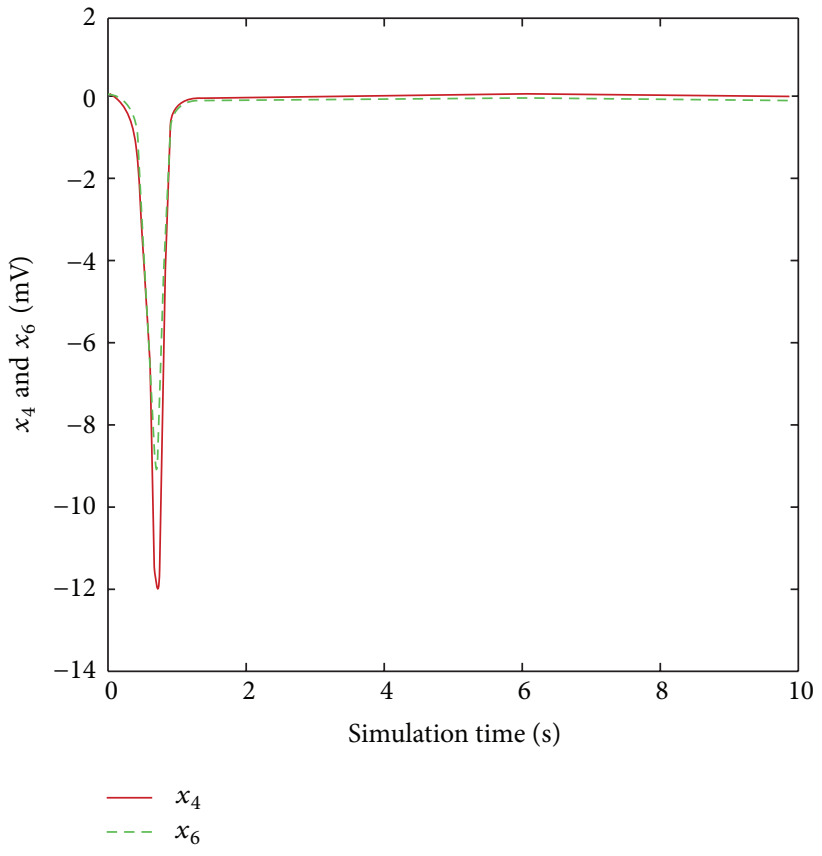

(b)

FIGURE 5: Synchronization of states $x_{4}, x_{6}$ with time delay befor control (a) and after control (b).

$$
\begin{aligned}
& +R_{15}\left(x_{1}-x_{5}\left(t-\tau_{15}\right)\right)+d_{2} x_{3}^{2} x_{4}-d_{2} x_{4} \\
& +d_{2} x_{2}-d_{2} x_{2}+c_{2} x_{3}+c_{2} x_{5}-c_{2} x_{5}-a_{2} \cos \omega t \\
& -R_{31}\left(x_{3}-x_{1}\left(t-\tau_{31}\right)\right)-R_{35}\left(x_{3}-x_{5}\left(t-\tau_{35}\right)\right)-u_{1}
\end{aligned}
$$

By substitution, we will have

$$
\begin{aligned}
\dot{e}_{2}= & -d_{1} x_{1}^{2} x_{2}+d_{2} x_{3}^{2} x_{4}+a_{1} \cos \omega t-a_{2} \cos \omega t \\
& +R_{13} e_{1}+R_{31} e_{1}-R_{35} e_{3}+R_{15} e_{1}+R_{15} e_{3} \\
& +d_{1} e_{2}+d_{1} x_{4}-c_{1} e_{1}-c_{1} x_{3}+d_{2} e_{2} \\
& -d_{2} x_{2}+c_{2} e_{3}+c_{2} x_{5}-u_{1} .
\end{aligned}
$$

Also,

$$
\begin{aligned}
\dot{e}_{2}= & -d_{1} x_{1}^{2} x_{2}+d_{2} x_{3}^{2} x_{4}+a_{1} \cos \omega t-a_{2} \cos \omega t \\
& +d_{1} x_{4}-c_{1} x_{3}-d_{2} x_{2}+c_{2} x_{5} \\
& +\left(R_{13}+R_{31}+R_{15}-c_{1}\right) e_{1} \\
& +\left(\widehat{d}_{2}+d_{1}\right) e_{2}+\left(-R_{35}+R_{15}+c_{2}\right) e_{3}-u_{1} .
\end{aligned}
$$

And control functions are as follows:

$$
\begin{aligned}
u_{1}= & -d_{1} x_{1}^{2} x_{2}+d_{2} x_{3}^{2} x_{4}+a_{1} \cos \omega t-a_{2} \cos \omega t \\
& +d_{1} x_{4}-c_{1} x_{3}-d_{2} x_{2}+c_{2} x_{5}+k_{1} e_{2} \\
& +k_{2} e_{2}+k_{3} e_{3} .
\end{aligned}
$$

Also,

$$
\begin{aligned}
\dot{e}_{4}= & \dot{x}_{4}-\dot{x}_{6}\left(t-\tau_{46}\right) \\
= & -d_{2} x_{3}^{2} x_{4}+d_{2} x_{4}+d_{2} x_{6}-d_{2} x_{6}-c_{2} x_{3} \\
& +c_{2} x_{5}-c_{2} x_{5}+a_{2} \cos \omega t-R_{31} e_{1} \\
& +R_{35} e_{3}+u_{1}+d_{3} x_{5}^{2} x_{6}-d_{3} x_{6} \\
& +d_{3} x_{4}-d_{3} x_{4}+c_{3} x_{5}-a_{3} \cos \omega t-u_{2} .
\end{aligned}
$$

By substitution, we will have

$$
\begin{aligned}
\dot{e}_{4}= & \dot{x}_{4}-\dot{x}_{6}\left(t-\tau_{46}\right) \\
= & -d_{2} x_{3}^{2} x_{4}+d_{3} x_{5}^{2} x_{6}+a_{2} \cos \omega t-a_{3} \cos \omega t \\
& -R_{31} e_{1}+R_{35} e_{3}+u_{1}+c_{3} x_{5} \\
& +R_{51} e_{1}+R_{51} e_{3}+R_{53} e_{3}+d_{2} e_{4}+d_{2} x_{6} \\
& -c_{2} e_{3}-c_{2} x_{5}+d_{3} e_{4}-d_{3} x_{4}-u_{2} .
\end{aligned}
$$

And control functions is as follows:

$$
\begin{aligned}
u_{2}= & -d_{2} x_{3}^{2} x_{4}+d_{3} x_{5}^{2} x_{6}+a_{2} \cos \omega t \\
& -a_{3} \cos \omega t+u_{1}+c_{3} x_{5}+d_{2} x_{6} \\
& -c_{2} x_{5}-d_{3} x_{4}+k_{4} e_{1}+k_{5} e_{3}+k_{6} e_{4}+k_{7}
\end{aligned}
$$

and matrix form of error equations is

$$
\dot{e}=A e .
$$




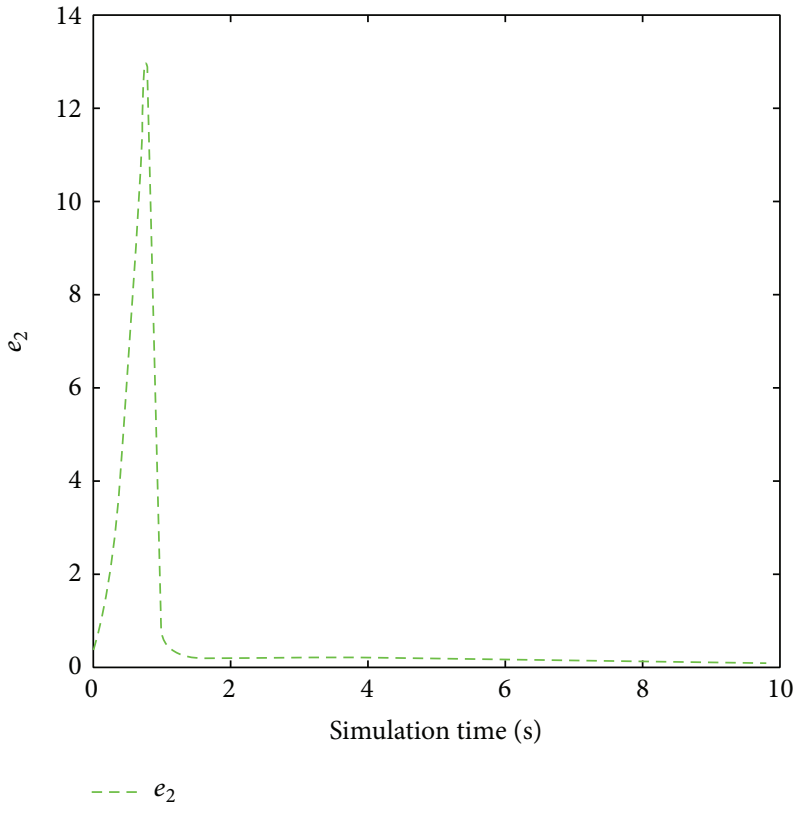

(a)

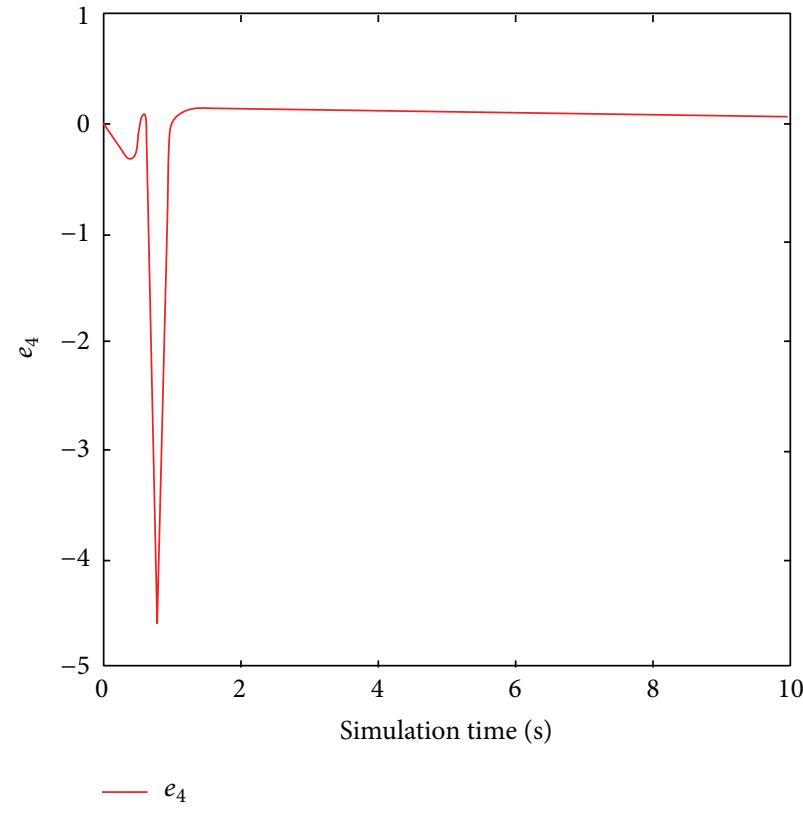

(b)

FIGURE 6: Error states $x_{2}, x_{4}$ and $x_{4}, x_{6}$ with time delay after control ((a), (b)).

In this case, the third oscillator acts as a pacemaker and its advantage is that instead of a sudden shock and a voltage of $D C$, it applies sinusoidal voltage for treatment.

Simulation diagrams related to synchronization in the case of three oscillators with time delay have been shown below. See Figures 4, 5, and 6 (the horizontal axis time (s) and the vertical axis millivolts).

\section{Conclusion}

In this paper, it has been explained that how simulating and curing some arrhythmias are possible, that one example of curing method, is modelling three-oscillator heart system in the state of delay and without delay and by applying an appropriate control.

In this paper after applying control $u$ to the model of three-oscillator heart system in case of time delay and without time delay and also observing of simulated diagrams corresponding to synchronization of this model, we observe that, the time of synchronization $x_{2}, x_{4}$ and $x_{4}, x_{6}$ and also the time when the error converges to zero in $x_{2}, x_{4}$ and $x_{4}$, $x_{6}$ after applying designed controller; in case of without time delay is less than 2(s), and in case of time delay less than 1.5(s).

These results indicate that the model of three-oscillator of the heart system in case of time delay and designed controller corresponding to synchronization of this model, is more appropriate and accurate than the state of without time delay.

\section{Conflict of Interests}

The authors declare that there is no conflict of interests regarding the publication of this paper.

\section{References}

[1] A. M. dos Santos, S. R. Lopes, and R. L. Viana, "Rhythm synchronization and chaotic modulation of coupled Van der Pol oscillators in a model for the heartbeat," Physica A, vol. 338, no. 3-4, pp. 335-355, 2004.

[2] D. Di Bernardo, M. G. Signorini, and S. Cerutti, "A model of two nonlinear coupled oscillators for the study of heartbeat dynamics," International Journal of Bifurcation and Chaos in Applied Sciences and Engineering, vol. 8, no. 10, pp. 1975-1985, 1998.

[3] B. B. Ferreira, A. S. de Paula, and M. A. Savi, "Chaos control applied to heart rhythm dynamics," Chaos, Solitons and Fractals, vol. 44, no. 8, pp. 587-599, 2011.

[4] L. Glass, "Synchronization and rhythmic processes in physiology," Nature, vol. 410, no. 6825, pp. 277-284, 2001.

[5] W. Thanom and R. N. K. Loh, "Observer-based nonlinear feedback controls for heartbeat ECG tracking systems," Intelligent Control and Automation, vol. 3, pp. 251-261, 2012.

[6] B. van der Pol and J. van der Mark, "The heartbeat considered as a relaxation oscillator and an electrical model of the heart," Philosophical Magazine and Journal of Science Series, vol. 7, supplement 6, pp. 763-775, 1928.

[7] S. R. F. S. M. Gois and M. A. Savi, "An analysis of heart rhythm dynamics using a three-coupled oscillator model," Chaos, Solitons and Fractals, vol. 41, no. 5, pp. 2553-2565, 2009.

[8] G. Gottwald and L. Melbourne, "A new test for chaos in deterministic systems," Nonlinear Dynamics, vol. 69, no. 3, pp. 1255-1262, 2012.

[9] C. Nguyen, Van Der Pol Oscillators Synchronization: Methods and Applications, 2009.

[10] L. M. Pecora and T. L. Carroll, "Synchronization in chaotic systems," Physical Review Letters, vol. 64, no. 8, pp. 821-824, 1990. 
[11] S. Sato, S. Doi, and T. Nomura, "Bonhoeffer-van der Pol Oscillator modelof the sino-atrial node: a possible mechanism of heart rate regulation," Methods of Information in Medicine, vol. 33, no. 1, pp. 116-119, 1994.

[12] H. Gholizade-Narm, A. Azemi, M. Khademi, and M. KarimiGhartemani, "A state observer and a synchronization method for heart pacemakers," Journal of Applied Sciences, vol. 8, no. 18, pp. 3175-3182, 2008.

[13] K. Rompala, R. Rand, and H. Howland, "Dynamics of three coupled van der Pol oscillators with application to circadian rhythms," Communications in Nonlinear Science and Numerical Simulation, vol. 12, no. 5, pp. 794-803, 2007.

[14] W. Thanom and R. N. K. Loh, "Nonlinear control of heartbeat models," Journal on Systemics, Cybernetics and Informatics, vol. 9, no. 1, pp. 21-27, 2009. 


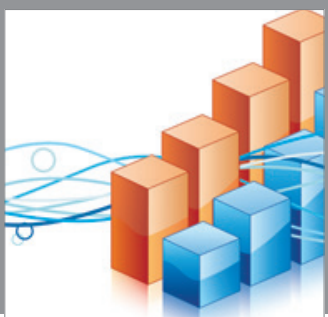

Advances in

Operations Research

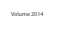

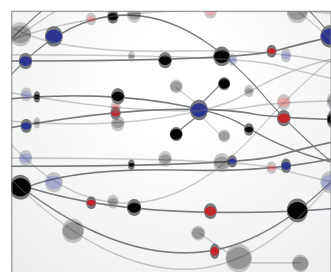

The Scientific World Journal
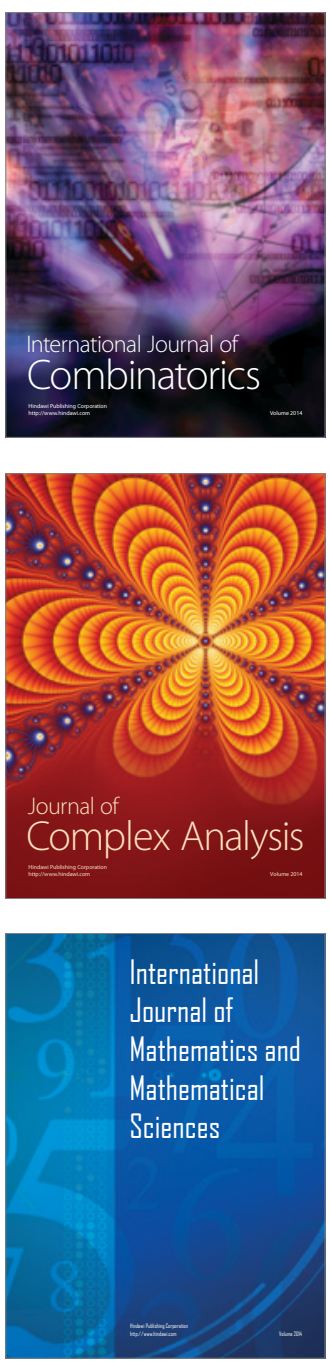

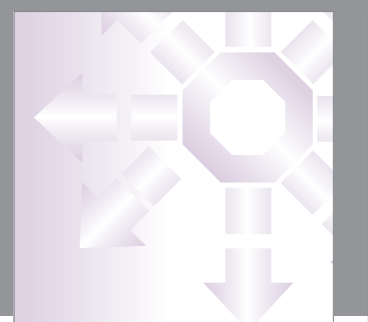

Advances in

Decision Sciences

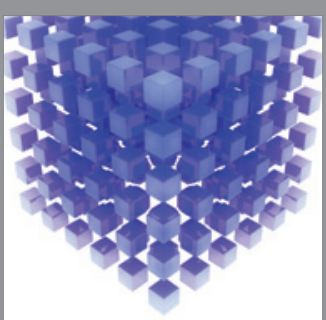

Mathematical Problems in Engineering

vament

\section{Algebra}

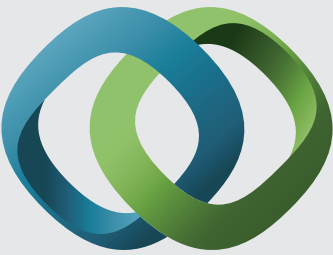

\section{Hindawi}

Submit your manuscripts at http://www.hindawi.com
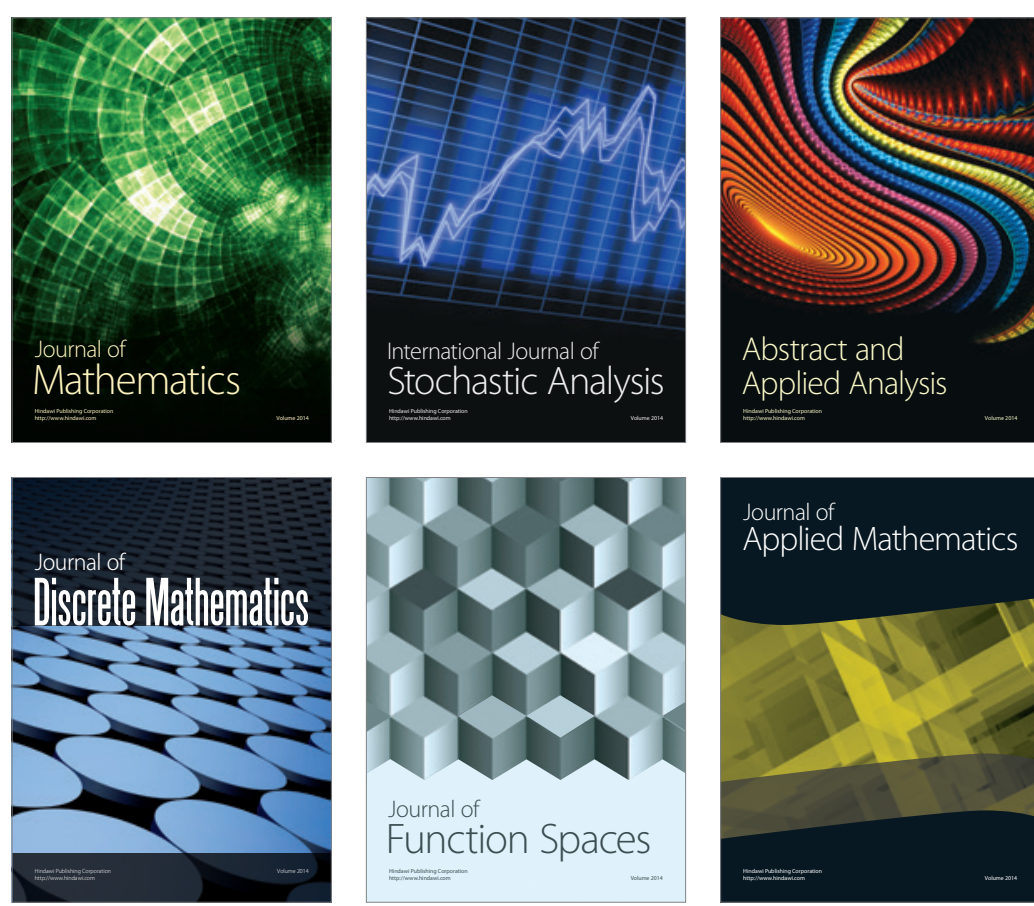

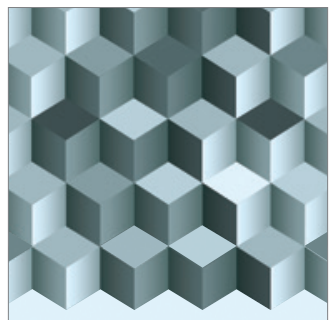

Journal of

Function Spaces

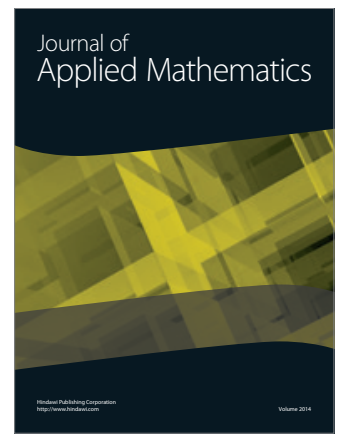

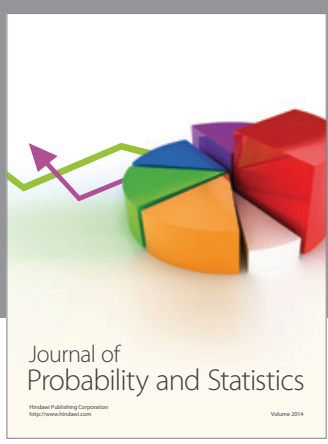
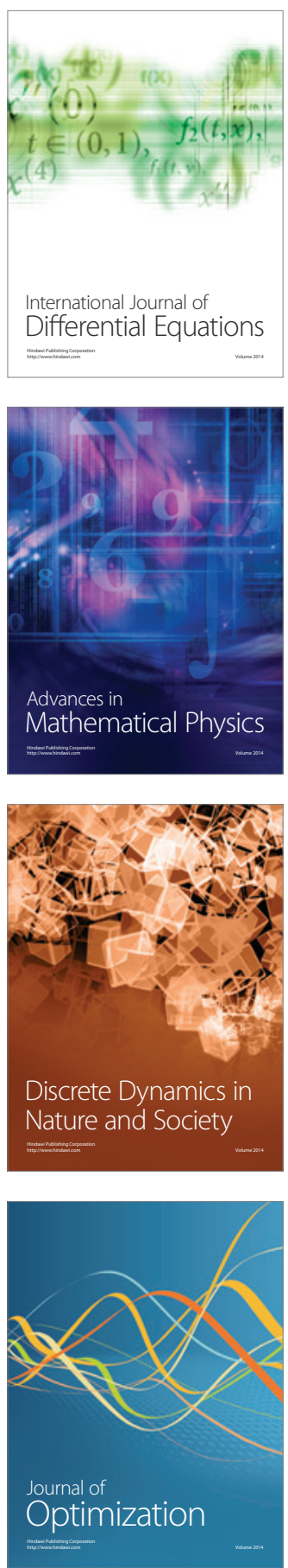